\title{
Review \\ Innovative Drugs to Treat Depression: Did Animal Models Fail to Be Predictive or Did Clinical Trials
} Fail to Detect Effects?

\author{
Catherine Belzung*,' \\ 'INSERM 930 and Université François Rabelais Tours, UFR Sciences et Techniques, Parc Grandmont, Tours, France
}

\begin{abstract}
Over recent decades, encouraging preclinical evidence using rodent models pointed to innovative pharmacological targets to treat major depressive disorder. However, subsequent clinical trials have failed to show convincing results. Two explanations for these rather disappointing results can be put forward, either animal models of psychiatric disorders have failed to predict the clinical effectiveness of treatments or clinical trials have failed to detect the effects of these new drugs. A careful analysis of the literature reveals that both statements are true. Indeed, in some cases, clinical efficacy has been predicted on the basis of inappropriate animal models, although the contrary is also true, as some clinical trials have not targeted the appropriate dose or clinical population. On the one hand, refinement of animal models requires using species that have better homological validity, designing models that rely on experimental manipulations inducing pathological features, and trying to model subtypes of depression. On the other hand, clinical research should consider carefully the results from preclinical studies, in order to study these compounds at the correct dose, in the appropriate psychiatric nosological entity or symptomatology, in relevant subpopulations of patients characterized by specific biomarkers. To achieve these goals, translational research has to strengthen the dialogue between basic and clinical science.

Neuropsychopharmacology (2014) 39, I04I-105I; doi: I0.1038/npp.2013.342; published online 22 January 2014
\end{abstract}

Keywords: depression; antidepressants; animal models; validity; treatments

\section{INTRODUCTION}

Major depressive disorder (MDD) is a very common mental disorder, mainly characterized by persistent anhedonia (inability to experience pleasure), apathy or lack of motivation, anxiety, and sadness. According to the World Health Organization (2008), MDD was ranked as the third leading cause of disability worldwide, and is predicted to worsen as it is expected to become the number one cause of the global burden of disease by 2030 (World Health Organization, 2008).

The first-line treatment of MDD is pharmacotherapy with antidepressants. The drugs that are currently used all share the property of increasing monoaminergic function as they impact the serotoninergic or the noradrenergic system by increasing availability of these neurotransmitters, either in a nonspecific way (eg, monoamine inhibitors or tricyclics impact both neurotransmission systems) or specifically on one of these two systems (eg, selective noradrenaline reuptake inhibitors or serotonin selective reuptake inhibitors (SSRIs)). However, even though these drugs are

\footnotetext{
*Correspondence: Professor C Belzung, INSERM 930 and Université François Rabelais Tours, UFR Sciences et Techniques, Parc Grandmont, Tours 37200, France. Tel:+3324736 69 94; Fax:+33 2473672 85; E-mail: catherine.belzung@univ-tours.fr

Received 6 August 2013; revised 13 December 2013; accepted 13 December 2013; accepted article preview online 18 December 2013
}

considered the primary treatment of MDD, a strong concern is that only one-third of MDD patients receiving antidepressants achieve complete remission of their symptoms after their first antidepressant therapy (Trivedi et al, 2006). This resistance to drugs can first be explained by nonspecific factors, such as hepatic drug metabolism (eg, variations of cytochrome P450; Yin et al, 2006; Mrazek et al, 2011) or insufficient penetrance into the brain of the compounds used (Kato et al, 2008; Lin et al, 2011; Uhr et al, 2008; Sarginson et al, 2010; Singh et al, 2012). Second, MDD is a complex pathology, associated with monoamines and also non-monoaminergic neurotransmitter systems (eg, GABA, glutamate, peptides, and cannabinoids), with alterations in signaling pathways (BDNF, tropomyosin-related kinase $B$ receptor, extracellular signal-regulated kinase, and Akt pathways) and with hormonal dysregulation (eg, of the hypothalamic-pituitary-adrenal (HPA) axis). Furthermore, in recent years, epigenetic modifications (histone acetylation and methylation), altered glial function (eg, astrocyte deficit), inflammation (excess of proinflammatory cytokines), and decreased neural plasticity (hippocampal neurogenesis, hippocampal, and cortical synaptogenesis) have also been described (see Krishnan and Nestler, 2008; Tanti and Belzung, 2010; Willner et al, 2012 for reviews). It is evident that some of these alterations cannot be reversed by increasing monoamines, so the development of innovative treatments targeting these dysfunctions could lead to 


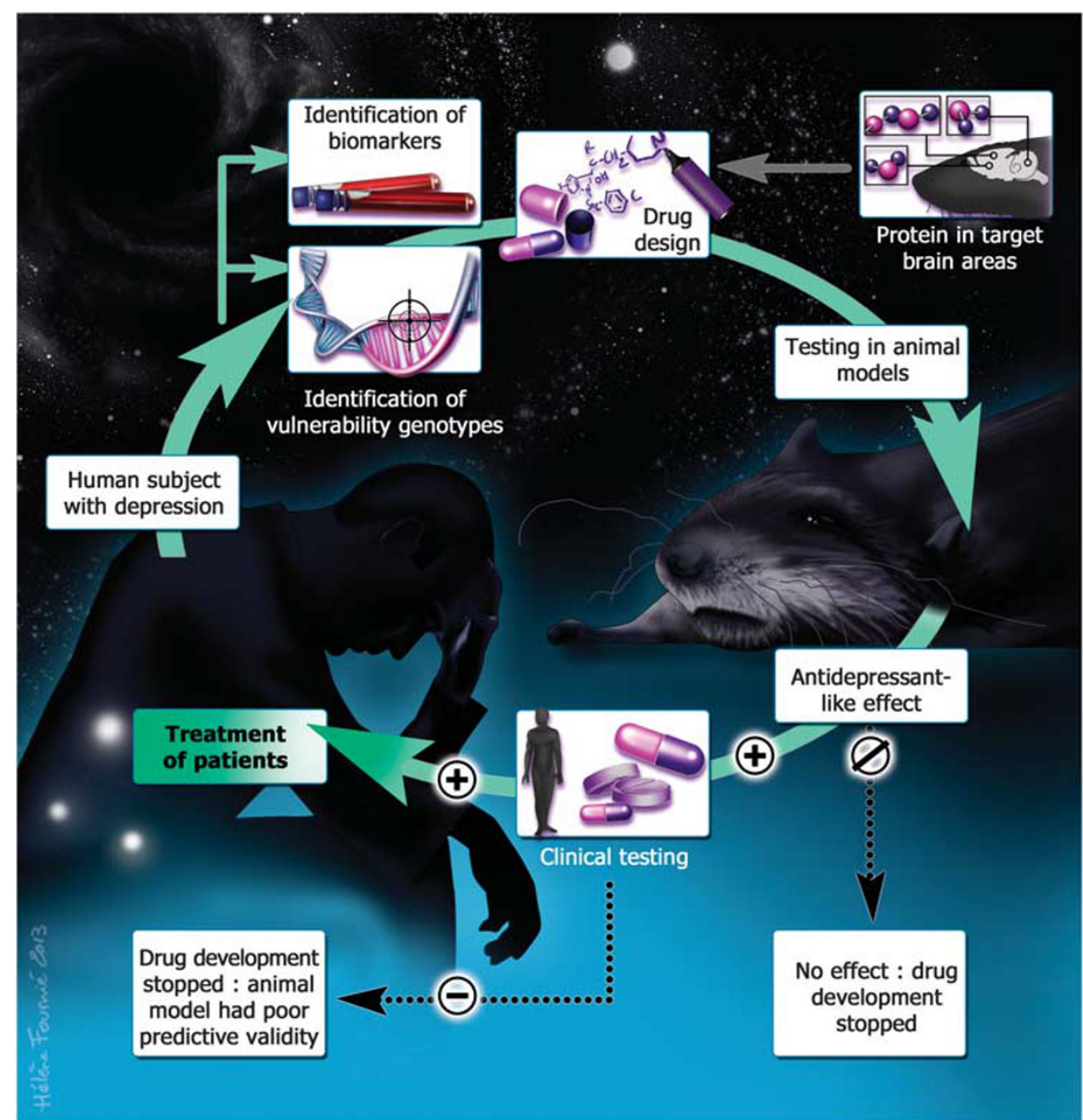

Figure I The different steps in the discovery of antidepressants. Abnormalities of some biomarkers (eg, as detected via plasma biochemical assays or molecular imaging) or polymorphism of some genes were first described in depressed patients. In some cases, preclinical research has already shown that some of the targets are expressed in crucial brain areas of rodents, eg, corticolimbic networks. Together, these findings enable pharmacological compounds targeting these dysfunctions to be designed. These drugs are then tested in animal models. It is important first to check whether the targets are expressed in a similar way in humans and the species that is going to be tested. In case no effect is detected (negative findings), clinical development is stopped (at this point, it is not possible to know whether the drug was a true negative or a false negative). In case an effect is found in different models, the drug/molecule can be tested in randomized double-blind clinical trials. When an effect is seen, it indicates that the drug was a true positive and patients can be treated with this drug. When the clinical trial does not reveal an antidepressant effect of the drug, the compound was a false positive.

the discovery of antidepressants of the future. This is generally the rationale for designing new targets (Figure 1): polymorphisms in some genes or changes in some biomarkers (seen via imaging or biochemical assays for example) are usually first detected in patients, enabling new compounds targeting this dysfunction to be developed. The actions of these drugs are then assessed using animal models. Although some of the alterations mentioned above cannot be targeted by drugs, others yield encouraging results (see Table 1 for an overview). For example, in the last two decades very promising preclinical data have been obtained targeting stress hormone changes. Corticotropin releasing factor receptor 1 (CRF1) and vasopressin receptor $1 \mathrm{~b}$ (V1b) antagonists have been developed, which reverse the HPA axis-related defects, and animal models have predicted a very high efficiency in treating MDD. Indeed, these molecules have generally shown antidepressant-like effects in several animal models of depression, in several species and on different behavioral readouts (Table 1). For example, CRF1 receptor antagonists have shown effects in three bioassays (forced swim test, tail suspension test, and DRL-72), in two species (mice and rats), and in three models (chronic stress, Flinder sensitive, and social stress). In addition, CRF1 receptor antagonists have shown anxiolytic effects in a wide range of anxiety tests and models (for a review see Griebel and Holmes, 2013). However, surprisingly, clinical trials undertaken using these drugs have frequently found negative results in MDD (Griebel and Holsboer, 2012), which questions the translational value of the initial findings. Indeed, concerning CRF1 antagonists, four studies out of five found it inactive in double blind controlled clinical trials. These disappointing findings could be explained either by inappropriate animal models for predicting clinical effects or possible defects 
Table I Monotherapy with Non-Monoaminergic Targets of Antidepressant Action in Patients with Major Depression or TreatmentResistant Depression: Effects in Clinical Trials and Predictions from Animal Models

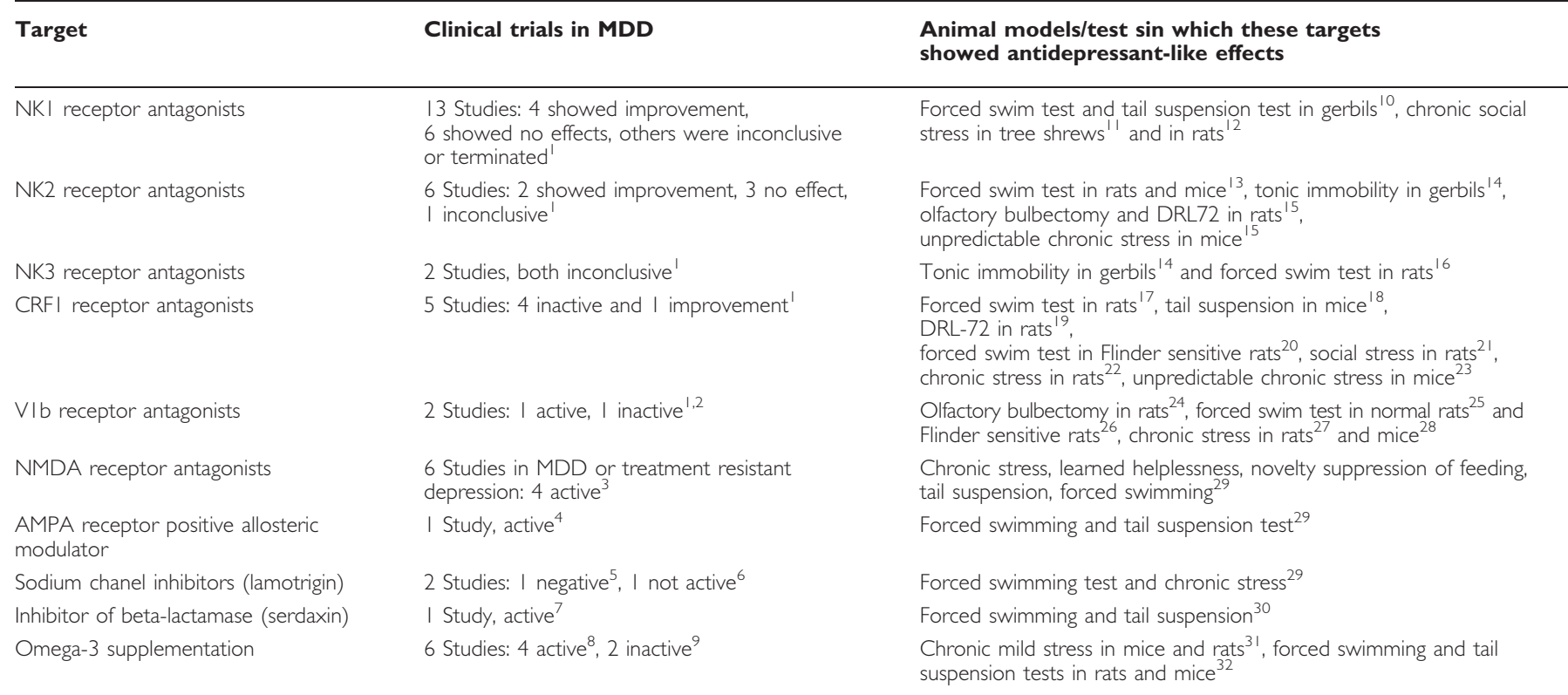

This table does not include compounds with a monoaminergic component (such as vortioxetine, quetiapine, or agomalatine), add-on therapies (in which a putative treatment is associated with a monoaminergic medication), or clinical trials targeting anxiety disorders or bipolar depression. NKI receptor antagonists tested in clinical trials in MDD include orvepitant, L-759274, CP-122721, casopitant, aprepitant. Saredutant and osanetant are, respectively, the sole NK2 and NK3 receptor antagonists tested clinically. CRF receptor antagonists investigated in clinical trials for the treatment of MDD include CP-3163II, NBI 30775 (RI21919), ONO-2333Ms, SSRI25543, and verucerfront (GSK56 1679). The sole VIb receptor antagonist tested clinically is SSR-I494I5. Clinically tested NMDA antagonists include the noncompetitive/high-affinity NMDA receptor antagonist ketamine, the non-competitive/low-affinity NMDA antagonist memantine, and the NR2B subunit-selective NMDA receptor antagonists CP-101, 606, and MK-0657. 'Griebel and Holsboer, 2012 (review); ${ }^{2}$ Griebel et al, $2012 ;{ }^{3}$ Mathews et al, 2012 (review); ${ }^{4}$ Nations et al, 20 I2; ${ }^{5}$ Santos et al, 2008; ${ }^{6}$ Barbee et al, 201 I; ${ }^{7}$ Riesenberg et al, 20 I 2; ${ }^{8}$ Freund-Levi et al, 2008; da Silva et al, 2008; Freeman et al, 20I I; Lespérance et al, 20I I; ${ }^{9}$ van de Rest et al, 2008; Bot et al, 2010 ; ' ${ }^{10}$ Varty et al, 2003; Wallace-Boone et al, 2008; '1 van der Hart et al, 2005; Czéh et al, 2005; ${ }^{12}$ Papp et al, 2000; ${ }^{13}$ Steinberg et al, 200 I; ${ }^{14}$ Salomé et al, 2006; ${ }^{15}$ Louis et al, 2008; ${ }^{16}$ Dableh et al, 2005; ${ }^{17}$ Jutkiewicz et al, 2005; ${ }^{18}$ Nielsen et al, 2004; ${ }^{19}$ Louis et al, 2006; ${ }^{20}$ Overstreet and Griebel, 2004; ${ }^{21}$ Wood et al, 2012; ${ }^{22}$ Sandi et al, 2008; ${ }^{23}$ Ducottet et al, 2003; Surget et al, 2008, 2009, 20II, Dournes et al, 20l3; ${ }^{24}$ Breuer et al, 2009; ${ }^{25} \mathrm{Griebel}$ et al, 2002 ;

${ }^{26}$ Overstreet and Griebel, 2005; ${ }^{27}$ Bessa et al, 2009; ${ }^{28}$ Griebel et al, 2002; Surget et al, 2008; ${ }^{29}$ Lapidus et al, 2013 (review); ${ }^{30}$ Mineur et al, 2007; ${ }^{31}$ Vancassel et al, 2008; Ferraz et al, 20I I; Naveen et al, 2013; ${ }^{32}$ Venna et al, 2009; Blondeau et al, 2009.

regarding the clinical data. This paper tries to address this issue, and to propose appropriate solutions.

\section{Did Animal Models Fail to be Predictive?}

The first issue concerns animal models of MDD. Several experimental manipulations have been designed to induce chronic depressive-like states in rodents, including early maternal deprivation, learned helplessness, social defeat, unpredictable chronic mild stress (UCMS), or chronic corticosterone administration (for an overview see Table 2; McArthur and Borsini, 2006; Markou et al, 2009; Cryan and Holmes, 2005). The changes induced can then be assessed either at the physiological level using corticosterone dosage, eg, or at the behavioral level using bioassays measuring resignation behavior, anhedonia, lack of motivation, etc (for a summary see Table 3 ). The failure to find new pharmacological treatments for this disease could be related to the inappropriateness of the animal models currently used to predict clinical outcomes correctly. In this case, animal models would generate a high number of false positive drugs: this research would detect antidepressantlike effects of compounds, which did not have such properties in clinical trials. This has indeed been observed in some cases (Markou et al, 2009; Rupniak, 2003), and may be due to insufficient external validity in translational research: results from the bench cannot be directly extrapolated to the bedside.

The failure of preclinical research to translate to the clinic could be due to poor validity of the animal situations used to model MDD. Our first example concerns poor homological validity relating to insufficient relevance of the species and of the strain chosen to construct the animal model (Belzung and Lemoine, 2011). It should be remembered that research has focused on the involvement of the tachykinin family, including substance $\mathrm{P}$, neurokinin $\mathrm{A}$, and neurokinin $\mathrm{B}$, in psychiatric disorders such as MDD (Ebner et al, 2009), and also on the relevance of these targets to treat these pathologies. Tachykinins interact with specific receptors particularly the NK1, NK2, and NK3 receptors (Regoli et al, 1994). Several studies have shown that the NK3 receptor antagonist osanetant induces antidepressant-like and anxiolytic-like effects in rodents (Dableh et al, 2005; Salomé et al, 2006). However, although rats, guinea pigs, and gerbils show a distribution of NK3 receptors similar to that found in some human brain areas relevant to MDD, such as in the cerebral cortex, the medial habenula, the 
Table 2 Animal Models of Depression Based on Experimental Manipulations Inducing Long-Lasting Behavioral and Neurobiological Changes

\begin{tabular}{llc}
\hline Animal model & Rationale & Reference \\
\hline $\begin{array}{l}\text { Repeated maternal } \\
\text { separation }\end{array}$ & $\begin{array}{l}\text { Inducing a strong vulnerability to depression by applying stressful } \\
\text { events during the developmental period (before weaning) }\end{array}$ & Millstein and Holmes, 2007 \\
$\begin{array}{l}\text { Spontaneous stress-prone } \\
\text { rats }\end{array}$ & $\begin{array}{l}\text { Using rats with spontaneous sensitivity to stress such as Flinders } \\
\text { sensitive line rat, Wistar Kyoto rat, fawn-hooded rat, learned helpless rat }\end{array}$ & Overstreet, 20 I2 \\
Learned helplessness & Inducing chronic behavioral despair by learning that a situation is without solution & Overmier and Seligman, I967 \\
Social defeat & Inducing chronic stress by repeated confrontation with a congener in & Berton et al, 2006 \\
Unpredictable chronic & Induch mice will experience social defeat & Willner et al, I992 \\
mild stress & Chronic mild stress based on the inability of the animals to predict their occurrence & David et al, 2009 \\
Chronic corticosterone & &
\end{tabular}

Table 3 Different Readouts Enabling Depression-Like Behavior in Rodents to be Assessed

\begin{tabular}{|c|c|c|}
\hline $\begin{array}{l}\text { Depression- } \\
\text { related } \\
\text { phenotype }\end{array}$ & Test & Reference \\
\hline Resignation & $\begin{array}{l}\text { Forced swimming } \\
\text { Tail suspension }\end{array}$ & $\begin{array}{l}\text { Porsolt et al, } 1978 \\
\text { Steru et al, } 1985\end{array}$ \\
\hline Lack of motivation & $\begin{array}{l}\text { Grooming behavior in the splash } \\
\text { test } \\
\text { Nest building in the nest test } \\
\text { Decrease in coat state score }\end{array}$ & $\begin{array}{l}\text { Santarelli et al, } 2003 \\
\text { Nollet et al, } 2013 \\
\text { Nollet et al, } 2013\end{array}$ \\
\hline Anhedonia & $\begin{array}{l}\text { Sucrose preference } \\
\text { Cookie test } \\
\text { Decreased intra-cranial self- } \\
\text { stimulation }\end{array}$ & $\begin{array}{l}\text { Willner et al, } 1987 \\
\text { Surget et al, 201 I } \\
\text { Moreau et al, } 1992\end{array}$ \\
\hline Anxiety & $\begin{array}{l}\text { Novelty-induced suppression of } \\
\text { feeding behavior }\end{array}$ & Dulawa and Hen, 2005 \\
\hline Irritability & Resident-intruder test & Mineur et al, 2003 \\
\hline
\end{tabular}

amygdala nuclei, the ventral tegmental area, and the dentate gyrus, outside these structures strong inter-species differences can be observed (Griebel and Beeské, 2012). For example, only the guinea pig possesses NK3 receptors in the lateral septum, whereas in the rat no NK3-binding sites can be detected in the thalamus. Interestingly, the distribution of NK3 receptors found in the guinea pig brain is close to that described in the human brain; this is also true for the pharmacological profile of NK3 receptors (Nguyen et al, 1994; Suman-Chauhan et al, 1994). Consequently, rats have poor homological validity for the investigation of the antistress properties of NK3 receptor ligands, while other species, such as guinea pigs, are fully appropriate. Using rats or mice in preclinical research investigating the effects of NK3 agents can thus lead to false negatives. It is probable that this observation also applies to other innovative targets, although inter-species comparisons of these molecular targets have not been conducted in a systematic way and are thus missing in many cases. Unfortunately, almost all animal models of MDD have been developed in rats or mice. Therefore, when human genetics or imaging studies undertaken in depressed subjects point to precise targets, it should first be verified that these targets are expressed in the model species in an appropriate way. If this is not the case, alternative species in which these targets are expressed in a homological way to humans should be used in designing models of depression. This requires prior extensive research on the biology and ethology of these species. Furthermore, homological validity not only requires choosing the appropriate species, but also identifying the relevant strain. For example, mice are characterized by a large phenotypic and genotypic variability, as more than 450 inbred strains have been described for this species (Beck et al, 2000). They vary for crucial phenotypes, such as stress sensitivity (Pothion et al, 2004; Ducottet and Belzung, 2005). In addition, mice are also the model species to design knockouts, knockdowns, or knockins of particular genes. Thus, the criteria to be used to choose the appropriate strain should be selected carefully. First, it is important to consider that knockout mice, deficient in one particular gene, are probably not appropriate to model MDD or psychiatric pathologies in general, as these diseases are not related to the absence of one particular gene. Appropriate models should focus on mice strains characterized by a high vulnerability to developing depressive-like behaviors; this includes strains bearing polymorphisms of particular genes involved in the etiology of MDD or strains characterized by poor maternal care (eg, BALB/c mice: Calatayud and Belzung, 2001, 2004), as this factor also largely contributes to the occurrence of depressive episodes in humans (Willner et al, 2012).

Another concern relates to the fact that drug effects have frequently been assessed using bio-assays such as the forced swimming test or the tail suspension test performed on normal animals, ie, in rodents that have not been subjected to experimental manipulations aimed at inducing a depression-like state. In humans, it is well documented that antidepressant therapy has substantial efficacy only in a sub-category of highly depressed subjects. In non-depressed patients, antidepressant efficacy is equivalent to placebo effects (Fournier et al, 2010; Khan et al, 2002; Kirsch et al, 2008). Therefore, it can be predicted that in rodents a similar picture should be found, namely that drugs should have no antidepressant-like effects in normal rodents subjected to these assays. If effects are detected in 'normal' rodents tested under these conditions, this argues against the predictive validity of these situations. Furthermore, in mice subjected to an UCMS, an experimental manipulation known to elicit biological and behavioral changes equivalent to those observed in humans with MDD (Sibille et al, 2009), it has also been shown that the effects of a chronic treatment with fluoxetine, a SSRI frequently used to treat MDD, elicit 
impressive changes in the expression of mRNA in various brain areas crucial for MDD, such as the dentate gyrus, the amygdala, and the cingulate cortex. Interestingly, in the cingulate cortex, the molecular changes induced by chronic fluoxetine were compared in mice subjected to UCMS or not, and no correlation of the molecular changes induced under these two conditions was found (Surget et al, 2009). This indicates that, at the molecular level, this SSRI does not elicit the same changes in normal mice and in those subjected to a protocol inducing a depressive-like state. Therefore, predictive validity (the ability of a model to predict drug efficacy: see McKinney and Bunney, 1969; Abramson and Seligman, 1977; Willner, 1984; Soubrié and Simon, 1989; Geyer and Markou, 1995; Koob et al, 1998; Sarter and Bruno, 2002; Weiss and Kilts, 1998 for further definitions) of a given compound has to be assessed in animals subjected to manipulations inducing a pathological state (eg, early environmental manipulations during the developmental period or stress-related manipulations during adulthood): when this is not the case the relevance and thus predictability may be poor. This is in line with findings that have shown that some putative antidepressants demonstrate effects only in rodents, which are either genetically stress-prone or have been placed in highly challenging conditions, such as stressful situations. For example, CRF receptor antagonists have poor effects in depression assays in animals that have not been stressed or that do not show high basal sustained activation of CRF receptors (for a review see Kehne and Cain, 2010). CRF antagonists might induce an effect only when these receptors have been activated by endogenous ligands such as CRF or urocortin, which is the case in stressful situations. It is also important to mention here that the experimental manipulations that are used to induce the depressive-like state should directly target the disease, and not comorbid pathologies. For example, chronic corticosterone administration has been used as a model of MDD (Fernandes et al, 1997; David et al, 2009) but this is in fact a model of Cushing's disease, a pathology highly comorbid with MDD, and not of MDD itself. Indeed, glucocorticoids per se are not sufficient to induce all aspects of stress exposure. It is probable that the subject requires concomitant occurrence of the context eliciting stress and of the associated hormonal component (ie, glucocorticoid release). This has recently been illustrated by Veenit et al (2013) who showed that corticosterone administration mimicked some (the aggressive component) but not all aspects of the depressive-like behavior (not the resignation component) related to stress. Interestingly, in patients suffering from Cushing's disease, a decrease in glucocorticoid synthesis or action rather than antidepressant therapy results in remission of the depressive symptoms (Pereira et al, 2010); therefore, high predictive validity of an animal model based on excessive glucocorticoids should in fact correspond to poor response to monoaminergic antidepressants, which seems not to be the case.

We have already reported that depression is characterized by a high proportion of treatment-resistant patients (see Introduction), ie, patients who do not show remission after monotherapy with monoaminergic drugs. New treatments that are effective in these patients therefore need to be designed, which also requires animal models of treatment-resistant depression. Few such models are available, particularly because response to classically used antidepressants is considered an important criterion to be fulfilled for the model to be considered valid for depression. Rodent models of treatment-resistant depression should thus be designed which do not respond to classical antidepressants and mimic some of the factors that are associated with treatment-resistant depression in humans. Some such models already exist: eg, the treatment resistance that is associated with high-fat diets has been translated to an animal model (Isingrini et al, 2010). Furthermore, reduced sensitivity to antidepressant therapy can also occur spontaneously in some strains of mice such as the BALB/ cOLaHsd strain (O'Leary et al, 2013).

Finally, in the clinic, sub-categories of MDD have been described, including atypical depression and melancholic depression. According to the DSM-IV-TR, atypical depression is characterized by mood reactivity (patients being able to experience improved mood in response to positive events), weight gain or increase in appetite, hypersomnia, and extreme reaction to negative events, whereas melancholic depression corresponds to anhedonia or mood non-reactivity (patients cannot experience positive moods, even when good things happen), early morning wakening, excessive guilt, anorexia, or weight loss. SSRIs and also monoamine inhibitors such as phenelzine, are usually quite effective in the treatment of atypical depression, whereas tricyclic antidepressants such as imipramine are not (Stewart et al, 1998). For example, Joyce et al (2002) compared the response to nortriptyline (a tricyclic antidepressant) and to fluoxetine (a SSRI) in patients suffering from atypical depression and they found a response rate of $67 \%$ with the SSRI, whereas there was no response with nortriptyline. This is associated with some biological features such as HPA axis hypoactivity (Anisman et al, 1999; Geracioti et al, 1997). On the other hand, Joyce et al (2002) reported that in melancholic patients, nortriptyline and fluoxetine were equally effective and that melancholic patients displayed high imipramine responsivity (Quitkin et al, 1989). Furthermore, in the melancholic subtype, the stress hormones cortisol, $\mathrm{ACTH}$, and CRF are hypersecreted (Wong et al, 2000), suggesting an HPA overdrive in melancholia. In most cases, animal models have been designed to model MDD rather than a sub-form of MDD. Therefore, the validity of these models could be greatly improved by providing models of MDD sub-types instead of MDD. This can be achieved in currently used models by assessing the status of the HPA axis and testing the efficacy of drugs belonging to different pharmacological classes. For example, tricyclics should be ineffective in an animal model of atypical depression.

\section{Did Clinical Research Fail to Detect Effects?}

Failure to provide adequate test situations to predict drug efficacy has not only been observed in some preclinical research, but is also true in some clinical trials designed without taking into account the predictions of the preclinical findings.

A first issue concerns the choice of the relevant dose to be used in the clinical trial. Indeed, it is well known that pharmacokinetic parameters (clearance and bioavailability) can differ across species and particularly between small mammals, such as rodents, and humans, thus an equivalent 
peripheral administration will induce very different plasma doses of the compound. As efficacy corresponds to a precise dose-response curve, an inappropriate plasma dose would logically induce failure to detect effects. For example, in mice, the NK2 receptor antagonist saredutant has repeatedly been tested in animal models of MDD, and it has shown effectiveness at doses of 10 and $30 \mathrm{mg} / \mathrm{kg}$ per os/per day, corresponding to a maximum plasma concentration (Cmax) ranging from 223 to $1390 \mathrm{ng} / \mathrm{ml}$. However, clinical trials used a dose of $100 \mathrm{mg} / \mathrm{day}$, corresponding to a very low Cmax of $28-49 \mathrm{ng} / \mathrm{ml}$, which is five times below the minimal effective dose in rodents (Griebel and Holsboer, 2012). This may clearly explain the negative findings from the clinical trials and it is probable that doses closer to the effective dose in rodents would have elicited positive results.

Another issue is an inappropriate choice of the disease targeted by the drug. For example, according to Griebel and Holsboer (2012), three clinical phase II and phase III trials have been undertaken to investigate the effects of CRF1 receptor antagonists in anxiety disorders: two of them investigated drug effects in social anxiety disorder and the other one in generalized anxiety disorder. Unfortunately, so far they have lacked compelling efficacy, which is not surprising. To our knowledge, data from animal models did not predict effects of these drugs in models of social anxiety or of generalized anxiety (in fact, no model has yet been designed for these pathologies), but instead predicted effects in disorders characterized by a high contribution of stress in the etiology, such as post-traumatic stress disorder (Philbert et al, 2013). It is probable that these compounds would induce encouraging results in this pathology, as predicted from animal models. However, this remains to be tested in clinical trials.

Another issue concerns patient stratification as MDD is not a homogeneous disorder. The biological alterations observed in this pathology are complex, and not necessarily present in all patients. For example, some patient subcategories exhibit altered HPA axis regulation, while others do not. The same heterogeneity can be found regarding alteration in neurotransmission, or in inflammation status. It can thus be that some MDD are related to an altered HPA axis, whereas others are due to increased levels of proinflammatory cytokines, decreased serotonin, etc (Tanti and Belzung, 2010). This has consequences regarding treatments used to reverse the symptomatology. It is possible to predict, eg, that only those patients who exhibit altered HPA axis regulation would benefit from treatment acting on stress hormones such as CRF1 receptor antagonists or V1b receptor antagonists. Similarly, only patients having increased pro-inflammatory cytokines would respond to a treatment targeting inflammation, and so forth. This means that stratification of patients based on available biomarkers is necessary to improve treatment response in order to identify patients according to the biological mechanism that is altered. Preclinical research might, in this case, enable researchers to define the mechanism targeted by the innovative drug; then clinical trials should select the clinical sub-population who exhibit alterations that corresponds to that particular treatment.

Finally, some theoretical models consider that MDD, as well as other psychiatric disorders, cannot be described as a unified entity but rather as a set of independent endophe- notypes, each corresponding to a specific genetic determinant, to a particular biological substrate and to a specific symptomatology (Hasler and Northoff, 2011). According to this theoretical framework, MDD corresponds to three main endophenotypes: increased self-focus, increased stress sensitivity, and anhedonia. Although the first of these, self-focus, is related to increased resting state of brain activity linked to heightened glutamatergic function and decreased GABAergic neurotransmission, the third, anhedonia, is associated with decreased monoaminegic function (serotonin, dopamine, and noradrenaline), and increased stress sensitivity to altered serotonin and GABA function. Genetic determinants of these dimensions include glutamatergic-, GABAergic-, and monoamine-related genes. If each of these dimensions is independent of the others and corresponds to a specific and drugable function, it would theoretically be possible to treat each of these symptoms separately. Preclinical research frequently tests a limited number of symptomatic dimensions. Although a well-validated model of MDD requires assessing a full set of dimensions rather than a sole endpoint, some preclinical research can show that a particular mechanism is involved in specific behavior. For example, hippocampal neurogenesis has been shown to be pivotal for some aspects of depressive-like behavior, such as latency to feed in the novelty-induced suppression of feeding test, but not for other behaviors, such as anxious behavior in an open field test or resignation behavior in the forced swimming test (David et al, 2009). This means that predictions of preclinical research in some cases concern drug effects on a MDD-related endophenotype, and not on MDD as a whole construct. Translating these findings to the clinic means that clinical trials should test innovative treatments on symptomatic dimensions related to that particular endophenoytpe, rather than on patients exhibiting all dimensions of MDD. Of course, this requires at the same time designing new methods to stratify the patients according to these dimensions, rather than through classical DSM-related diagnostic features or classical depression scales. However, the precise way to achieve this goes beyond the scope of this review. Similarly, if animal research enables predictions about subcategories of MDD (such as atypical or melancholic depression) to be made, clinical research should take them into account when assessing efficacy of drugs in patients.

\section{Solutions to Improve the Translational Value of Psychiatric Research}

Solutions to improve the translational value of findings in the field of psychiatric research can easily be drawn up and are summarized in Table 4. They concern the ways to improve animal models and clinical trials, and also the transition from animal models to clinical trials.

In the field of animal models, homological validity can be improved by designing new models in species that are not currently used. As homological validity is certainly higher in mammals than in other vertebrates (Belzung and Philippot, 2007), because of the proximity of the central nervous system (only mammals have a well-developed neocortex) and of some cognitive processes involved in psychiatric conditions (mainly executive functions such as flexibility and inhibition), this means that new mammals 
Table 4 Drawbacks of Present Translational Research and Proposed Future Directions

\begin{tabular}{ll}
\hline Present situation & Future directions \\
\hline Lack of homological validity of animal models & Study the biology and ethology of new mammalian species such as gerbils or guinea pigs \\
Lack of pathological validity of animal models & Use models in which animals have been rendered pathological via experimental manipulations \\
Lack of refinement of preclinical situations & Design models of subtypes of pathology or models of endophenotypes \\
Predictions from animal models not taken into account & Separate patients according to biological markers and use patients who score high on depression scales \\
Inappropriate dose used in the clinical trials & Calculate equivalent Cmax \\
& Use humanized mouse lines expressing human P450s enzymes
\end{tabular}

should be used in preclinical studies. Consequently, research should be undertaken to carefully investigate the biology, genetics, and ethology of these species. Other aspects of validity of the animal models can also certainly be improved, by designing models based on experimental manipulations inducing a pathological-like state, and particularly by trying to find situations that would mimic sub-categories of the disorders, or particular dimensions or endophenotypes linked to a disorder. The sex aspect should also be taken into account more. Indeed, women are more prone to stress-related psychiatric disorders such as MDD (Holden, 2005) and sex differences have already been shown in animal models of MDD as female rodents display higher immobility than males in the forced swim test, whereas they do not respond in the learned helplessness paradigm (Dalla et al, 2011). Furthermore, after chronic mild stress, the modification in sucrose intake is seen mainly in males, whereas the HPA axis dysfunction is observed mainly in females (Dalla et al, 2011). Animal models should be developed that take the higher female prevalence of MDD into account. Finally, animal models can also be greatly improved by trying to improve the translation of the clinical findings. In many cases, clinical research has established changes in some biomarkers detected via imaging or plasma assays or associated genetic polymorphisms linked to a pathological state: these alterations can also be a starting point for designing new animal models.

Pharmacokinetic concerns could also be addressed, by developing better models for inter-species differences in pharmacokinetics. This involves both clinical and preclinical research. This can be achieved in different ways. In some cases, the appropriate dosage can reasonably be extrapolated from the preclinical findings, using specific formulae to calculate the relevant doses according to the species (Lin, 1998; Martignoni et al, 2006). In other cases, this appears more complicated. Interspecies variations are mainly related to differences in the expression and catalytic activity of hepatic P450 enzymes (Caldwell, 1981; Bogaards et al, 2000), as 102 functional P450 genes have been identified in the mouse genome compared with 57 in humans (Nelson et al, 2004). A way to address this difficulty consists in using humanized mouse lines expressing human P450 enzymes to test the effectiveness of innovative targets (Cheung and Gonzalez, 2008). Interestingly, this has already been carried out in antidepressant-related research (Shen and Yu, 2009).

Clinical research could also be improved. Patients who would respond to innovative therapeutics should be more carefully chosen, particularly by focusing on patients scoring very high on MDD scales in order to avoid false negatives because of patients who were not clinically depressed, but only suffering from normal sadness, which does not respond to antidepressant therapy. Indeed, currently this is not the case and many clinical trials have been undertaken with patients scoring low on depression scales. Finally, animal models generally enable precise predictions about the therapeutic target as they describe under which conditions a given drug is effective. For example, drugs targeting the stress axis are effective when the HPA system has been challenged, such as by high stressful conditions, but not under more basal conditions. Patients should therefore be stratified according to these predictions, which would considerably increase the probability of finding positive effects in clinical trials. Finally, clinical trials should shift from a DSM-based nosology to studies based on the detection and characterization of the relevant endophenotypes that would respond to a particular treatment.

\section{CONCLUSION}

In conclusion, failure to find new therapies that would result in an effective translation between the preclinical and clinical research is mainly due to insufficient dialogue between preclinical scientists such as fundamental neuroscientists, and medical doctors such as psychiatrists. Progress in this field and therapeutic innovations would result from improved reciprocal exchanges between protagonists in these two fields. Scientific societies as well as funding agencies should encourage this dialogue by providing adequate structures, whereas scientists and practitioners should become more open minded in fully incorporating the findings from the two fields using an integrated, cogenerative method. Beyond research on innovative treatments for MDD, this applies more generally to finding new drugs in the field of psychiatry, and even, in some cases, in non-psychiatric pathologies.

\section{FUNDING AND DISCLOSURE}

The author declares no conflict of interest.

\section{ACKNOWLEDGEMENTS}

We are thankful to Vicki Wing and Sue Edrich for corrections in the English language.

\section{REFERENCES}

Abramson LY, Seligman MEP (1977). Modeling psychopathology in the laboratory: history and rationale. In: Maser JD, Seligman 
MEP (eds). Psychopathology: Experimental Models. WH Freeman: San Francisco, pp 1-26.

Anisman H, Ravindran AV, Griffiths J, Merali Z (1999). Endocrine and cytokine correlates of major depression and dysthymia with typical or atypical features. Mol Psychiatry 4: 182-188.

Barbee JG, Thompson TR, Jamhour NJ, Stewart JW, Conrad EJ, Reimherr FW et al (2011). A double-blind placebo-controlled trial of lamotrigine as an antidepressant augmentation agent in treatment-refractory unipolar depression. J Clin Psychiatry 72: $1405-1012$

Beck JA, Lloyd S, Hafezparast M, Lennon-Pierce M, Eppig JT, Festing MF et al (2000). Genealogies of mouse inbred strains. Nat Genet 24: 23-25.

Belzung C, Philippot P (2007). Anxiety from a phylogenetic perspective: Is there a qualitative difference between human and animal anxiety? Neural Plast 2007: 59676.

Belzung C, Lemoine M (2011). Criteria of validity for animal models of psychiatric disorders: focus on anxiety disorders and depression. Biol Mood Anxiety Disord 1: 9.

Berton O, McClung CA, Dileone RJ, Krishnan V, Renthal W, Russo SJ et al (2006). Essential role of BDNF in the mesolimbic dopamine pathway in social defeat stress. Science 311: 864-868.

Bessa JM, Ferreira D, Melo I, Marques F, Cerqueira JJ, Palha JA et al (2009). The mood-improving actions of antidepressants do not depend on neurogenesis but are associated with neuronal remodeling. Mol Psychiatry 14: 764-773.

Blondeau N, Nguemeni C, Debruyne DN, Piens M, Wu X, Pan H et al (2009). Subchronic alpha-linolenic acid treatment enhances brain plasticity and exerts an antidepressant effect: a versatile potential therapy for stroke. Neuropsychopharmacology 34: 2548-2559.

Bogaards JJ, Bertrand M, Jackson P, Oudshoorn MJ, Weaver RJ, van Bladeren PJ et al (2000). Determining the best animal model for human cytochrome P450 activities: a comparison of mouse, rat, rabbit, dog, micropig, monkey and man. Xenobiotica 30: $1131-1152$

Bot M, Pouwer F, Assies J, Jansen EH, Diamant M, Snoek FJ et al (2010). Eicosapentaenoic acid as an add-on to antidepressant medication for co-morbid major depression in patients with diabetes mellitus: a randomized, double-blind placebo-controlled study. J Affect Disord 126: 282-286.

Breuer ME, van Gaalen MM, Wernet W, Claessens SE, Oosting RS, Behl B et al (2009). SSR149415, a non-peptide vasopressin V1b receptor antagonist, has long-lasting antidepressant effects in the olfactory bulbectomy-induced hyperactivity depression model. Naunyn Schmiedebergs Arch Pharmacol 379: 101-106.

Calatayud F, Belzung C (2001). Emotional reactivity in mice, a case of nongenetic heredity? Physiol Behav 74: 355-362.

Calatayud F, Coubard S, Belzung C (2004). Emotional reactivity in mice may not be inherited but influenced by parents. Physiol Behav 80: 465-474.

Caldwell J (1981). The current status of attempts to predict species differences in drug metabolism. Drug Metab Rev 12: 221-237.

Cheung C, Gonzalez FJ (2008). Humanized mouse lines and their application for prediction of human drug metabolism and toxicological risk assessment. J Pharmacol Exp Ther 327: 288-299.

Cryan JF, Holmes A (2005). The ascent of mouse: advances in modelling human depression and anxiety. Nat Rev Drug Discov 4: 775-790.

Czéh B, Pudovkina O, van der Hart MG, Simon M, Heilbronner U, Michaelis $\mathrm{T}$ et al (2005). Examining SLV-323, a novel NK1 receptor antagonist, in a chronic psychosocial stress model for depression. Psychopharmacology (Berl) 180: 548-557.

Dableh LJ, Yashpal K, Rochford J, Henry JL (2005). Antidepressant-like effects of neurokinin receptor antagonists in the forced swim test in the rat. Eur J Pharmacol 507: 99-105.
Dalla C, Pitychoutis PM, Kokras N, Papadopoulou-Daifoti Z (2011). Sex differences in response to stress and expression of depressive-like behaviours in the rat. Curr Top Behav Neurosci 8: 97-118.

da Silva TM, Munhoz RP, Alvarez C, Naliwaiko K, Kiss A, Andreatini $\mathrm{R}$ et al (2008). Depression in Parkinson's disease: a double-blind, randomized, placebo-controlled pilot study ofomega-3 fatty-acid supplementation. J Affect Disord 111: 351-359.

David DJ, Samuels BA, Rainer Q, Wang JW, Marsteller D, Mendez I et al (2009). Neurogenesis-dependent and -independent effects of fluoxetine in an animal model of anxiety/depression. Neuron 62: 479-493.

Dournes C, Beeské S, Belzung C, Griebel G (2013). Deep brain stimulation in treatment-resistant depression in mice: comparison with the CRF1 antagonist, SSR125543. Prog Neuropsychopharmacol Biol Psychiatry 40: 213-220.

Ducottet C, Belzung C (2005). Correlations between behaviours in the elevated plus-maze and sensitivity to unpredictable subchronic mild stress: evidence from inbred strains of mice. Behav Brain Res 156: 153-162.

Ducottet C, Griebel G, Belzung C (2003). Effects of the selective nonpeptide corticotropin-releasing factor receptor 1 antagonist antalarmin in the chronic mild stress model of depression in mice. Prog Neuropsychopharmacol Biol Psychiatry 27: 625-631.

Dulawa SC, Hen R (2005). Recent advances in animal models of chronic antidepressant effects: the novelty-induced hypophagia test. Neurosci Biobehav Rev 29: 771-783.

Ebner K, Sartori SB, Singewald N (2009). Tachykinin receptors as therapeutic targets in stress-related disorders. Curr Pharm Des 15: $1647-1674$.

Fernandes C, McKittrick CR, File SE, McEwen BS (1997). Decreased 5-HT1A and increased 5-HT2A receptor binding after chronic corticosterone associated with a behavioural indication of depression but not anxiety. Psychoneuroendocrinology 22: 477-491.

Ferraz AC, Delattre AM, Almendra RG, Sonagli M, Borges C, Araujo P et al (2011). Chronic $\omega-3$ fatty acids supplementation promotes beneficial effects on anxiety, cognitive and depressivelike behaviors in rats subjected to a restraint stress protocol. Behav Brain Res 219: 116-122.

Fournier JC, DeRubeis RJ, Hollon SD, Dimidjian S, Amsterdam JD, Shelton RC et al (2010). Antidepressant drug effects and depression severity: a patient-level meta-analysis. JAMA 303: 47-53.

Freeman MP, Hibbeln JR, Silver M, Hirschberg AM, Wang B, Yule $\mathrm{AM}$ et al (2011). Omega-3 fatty acids for major depressive disorder associated with the menopausal transition: a preliminary open trial. Menopause 18: 279-284.

Freund-Levi Y, Basun H, Cederholm T, Faxén-Irving G, Garlind A, Grut $\mathrm{M}$ et al (2008). Omega-3 supplementation in mild to moderate Alzheimer's disease: effects on neuropsychiatric symptoms. Int J Geriatr Psychiatry 23: 161-169.

Geracioti TD Jr, Loosen PT, Orth DN (1997). Low cerebrospinal fluid corticotropin-releasing hormone concentrations in eucortisolemic depression. Biol Psychiatry 42: 165-174.

Geyer MA, Markou A (1995). Animal models of psychiatric disorders. In: Bloom FE, Kupfer DJ (eds) Psychopharmacology: the Fourth Generation of Progress. Raven Press: New York, pp 787-798.

Griebel G, Beeské S (2012). Is there still a future for neurokinin 3 receptor antagonists as potential drugs for the treatment of psychiatric diseases? Pharmacol Ther 133: 116-123.

Griebel G, Holsboer F (2012). Neuropeptide receptor ligands as drugs for psychiatric diseases: the end of the beginning? Nat Rev Drug Discov 11: 462-478.

Griebel G, Holmes A (2013). 50 years of hurdles and hope in anxiolytic drug discovery. Nat Rev Drug Discov 12: 667-687. 
Griebel G, Simiand J, Serradeil-Le Gal C, Wagnon J, Pascal M, Scatton B et al (2002). Anxiolytic- and antidepressant-like effects of the non-peptide vasopressin $\mathrm{V} 1 \mathrm{~b}$ receptor antagonist, SSR149415, suggest an innovative approach for the treatment of stress-related disorders. Proc Natl Acad Sci USA 99: 6370-6375.

Griebel G, Beeské S, Stahl SL (2012). The vasopressin V(1b) receptor antagonist SSR149415 in the treatment of major depressive and generalized anxiety disorders: results from 4 randomized, double-blind, placebo-controlled studies. J Clin Psychiatry 73: 1403-1411.

Hasler G, Northoff G (2011). Discovering imaging endophenotypes for major depression. Mol Psychiatry 16: 604-619.

Holden C (2005). Sex and the suffering brain. Science 308: 1574.

Isingrini E, Camus V, Le Guisquet AM, Pingaud M, Devers S, Belzung C (2010). Association between repeated unpredictable chronic mild stress (UCMS) procedures with a high fat diet: a model of fluoxetine resistance in mice. PLoS One 5: e10404.

Joyce PR, Mulder RT, Luty SE, Sullivan PF, McKenzie JM, Abbott $\mathrm{RM}$ et al (2002). Patterns and predictors of remission, response and recovery in major depression treated with fluoxetine or nortriptyline. Aust NZ J Psychiatry 36: 384-391.

Jutkiewicz EM, Wood SK, Houshyar H, Hsin LW, Rice KC, Woods $\mathrm{JH}$ (2005). The effects of CRF antagonists, antalarmin, CP154,526, LWH234, and R121919, in the forced swim test and on swim-induced increases in adrenocorticotropin in rats. Psychopharmacology (Berl) 180: 215-223.

Kato M, Fukuda T, Serretti A, Wakeno M, Okugawa G, Ikenaga Y et al (2008). ABCB1 (MDR1) gene polymorphisms are associated with the clinical response to paroxetine in patients with major depressive disorder. Prog Neuropsychopharmacol Biol Psychiatry 32: $398-404$

Kehne JH, Cain CK (2010). Therapeutic utility of non-peptidic CRF1 receptor antagonists in anxiety, depression, and stressrelated disorders: evidence from animal models. Pharmacol Ther 128: 460-487.

Khan A, Leventhal RM, Khan SR, Brown WA (2002). Severity of depression and response to antidepressants and placebo: an analysis of the Food and Drug Administration database. J. Clin Psychopharmacol 22: 40-45.

Kirsch I, Deacon BJ, Huedo-Medina TB, Scoboria A, Moore TJ, Johnson BT (2008). Initial severity and antidepressant benefits: a meta-analysis of data submitted to the Food and Drug Administration. PLoS Med 5: e45.

Koob GF, Heinrichs SC, Britton K (1998). Animal models of anxiety disorders. In: Schatzberg AF, Nemeroff CB (eds) The American Psychiatric Press Textbook of Psychopharmacology. American Psychiatric Press: Washington DC-London, pp 133-144.

Krishnan V, Nestler EJ (2008). The molecular neurobiology of depression. Nature 455: 894-902.

Lapidus KA, Soleimani L, Murrough JW (2013). Novel glutamatergic drugs for the treatment of mood disorders. Neuropsychiatr Dis Treat 9: 1101-1112.

Lespérance F, Frasure-Smith N, St-André E, Turecki G, Lespérance P, Wisniewski SR (2011). The efficacy of omega-3 supplementation for major depression: a randomized controlled trial. J Clin Psychiatry 72: 1054-1062.

Lin JH (1998). Applications and limitations of interspecies scaling and in vitro extrapolation in pharmacokinetics. Drug Metab Dispos 26: 1202-1212.

Lin KM, Chiu YF, Tsai IJ, Chen CH, Shen WW, Liu SC et al (2011). $\mathrm{ABCB} 1$ gene polymorphisms are associated with the severity of major depressive disorder and its response to escitalopram treatment. Pharmacogenet Genomics 21: 163-170.

Louis C, Cohen C, Depoortère R, Griebel G (2006). Antidepressantlike effects of the corticotropin-releasing factor 1 receptor antagonist, SSR125543, and the vasopressin 1b receptor antagonist, SSR149415, in a DRL-72s schedule in the rat. Neuropsychopharmacology 31: 2180-2187.
Louis C, Stemmelin J, Boulay D, Bergis O, Cohen C, Griebel G (2008). Additional evidence for anxiolytic- and antidepressantlike activities of saredutant (SR48968), an antagonist at the neurokinin-2 receptor in various rodent-models. Pharmacol Biochem Behav 89: 36-45.

Markou A, Chiamulera C, Geyer MA, Tricklebank M, Steckler T (2009). Removing obstacles in neuroscience drug discovery: the future path for animal models. Neuropsychopharmacology 34: 74-89.

Martignoni M, Groothuis GM, de Kanter R (2006). Species differences between mouse, rat, dog, monkey and human CYPmediated drug metabolism, inhibition and induction. Expert Opin Drug Metab Toxicol 2: 875-894.

Mathews DC, Henter ID, Zarate CA (2012). Targeting the glutamatergic system to treat major depressive disorder: rationale and progress to date. Drugs 72: 1313-1333.

McArthur R, Borsini F (2006). Animal models of depression in drug discovery: a historical perspective. Pharmacol Biochem Behav 84: 436-452.

McKinney WT Jr, Bunney WE Jr (1969). Animal model of depression. I: Review of evidence: implications for research. Arch Gen Psychiatry 21: 240-28.

Millstein RA, Holmes A (2007). Effects of repeated maternal separation on anxiety- and depression-related phenotypes in different mouse strains. Neurosci Biobehav Rev 31: 3-17.

Mineur YS, Prasol DJ, Belzung C, Crusio WE (2003). Agonistic behavior and unpredictable chronic mild stress in mice. Behav Genet 33: 513-519.

Mineur YS, Picciotto MR, Sanacora G (2007). Antidepressant-like effects of ceftriaxone in male C57BL/6J mice. Biol Psychiatry 61: $250-252$.

Moreau JL, Jenck F, Martin JR, Mortas P, Haefely WE (1992). Antidepressant treatment prevents chronic unpredictable mild stress-induced anhedonia as assessed by ventral tegmentum self-stimulation behavior in rats. Eur Neuropsychopharmacol 2: 43-49.

Mrazek DA, Biernacka JM, O'Kane DJ, Black JL, Cunningham JM et al (2011). CYP2C19 variation and citalopram response. Pharmacogenet Genomics 21: 1-9.

Nations KR, Dogterom P, Bursi R, Schipper J, Greenwald S, Zraket $\mathrm{D}$ et al (2012). Examination of Org 26576, an AMPA receptor positive allosteric modulator, in patients diagnosed with major depressive disorder: an exploratory, randomized, double-blind, placebo-controlled trial. J Psychopharmacol 26: $1525-1539$.

Naveen S, Siddalingaswamy M, Singsit D, Khanum F (2013). Antidepressive effect of polyphenols and omega-3 fatty acid from pomegranate peel and flax seed in mice exposed to chronic mild stress. Psychiatry Clin Neurosci 67: 501-508.

Nelson DR, Zeldin DC, Hoffman SMG, Maltais LJ, Wain HM, Nebert DW (2004). Comparison of cytochrome P450 (CYP) genes from the mouse and human genomes, including nomenclature recommendations for genes, pseudogenes and alternative-splice variants. Pharmacogenetics 14: 1-18.

Nguyen QT, Jukic D, Chretien L, Gobeil F, Boussougou M, Regoli D (1994). Two NK-3 receptor subtypes: Demonstration by biological and binding assays. Neuropeptides 27: 157-161.

Nielsen DM, Carey GJ, Gold LH (2004). Antidepressant-like activity of corticotropin-releasing factor type-1 receptor antagonists in mice. Eur J Pharmacol 499: 135-146.

Nollet M, Le Guisquet AM, Belzung C (2013). Models of depression: unpredictable chronic mild stress in mice. Curr Protoc Pharmacol Chapter 5: Unit 5.65.

O'Leary OF, Zandy S, Dinan TG, Cryan JF (2013). Lithium augmentation of the effects of desipramine in a mouse model of treatment-resistant depression: a role for hippocampal cell proliferation. Neuroscience 228: 36-46. 
Overmier JB, Seligman ME (1967). Effects of inescapable shock upon subsequent escape and avoidance responding. J Comp Physiol Psychol 63: 28-33.

Overstreet DH (2012). Modeling depression in animal models. Methods Mol Biol 829: 125-144.

Overstreet DH, Griebel G (2004). Antidepressant-like effects of CRF1 receptor antagonist SSR125543 in an animal model of depression. Eur J Pharmacol 497: 49-53.

Overstreet DH, Griebel G (2005). Antidepressant-like effects of the vasopressin V1b receptor antagonist SSR149415 in the Flinders Sensitive Line rat. Pharmacol Biochem Behav 82: 223-227.

Papp M, Vassout A, Gentsch C (2000). The NK1-receptor antagonist NKP608 has an antidepressant-like effect in the chronic mild stress model of depression in rats. Behav Brain Res 115: 19-23.

Pereira AM, Tiemensma J, Romijn JA (2010). Neuropsychiatric disorders in Cushing's syndrome. Neuroendocrinology 92(Suppl 1): $65-70$.

Philbert J, Belzung C, Griebel G (2013). The CRF(1) receptor antagonist SSR125543 prevents stress-induced cognitive deficit associated with hippocampal dysfunction: comparison with paroxetine and D-cycloserine. Psychopharmacology 228: 97-107.

Porsolt RD, Anton G, Blavet N, Jalfre M (1978). Behavioural despair in rats: a new model sensitive to antidepressant treatments. Eur J Pharmacol 47: 379-391.

Pothion S, Bizot JC, Trovero F, Belzung C (2004). Strain differences in sucrose preference and in the consequences of unpredictable chronic mild stress. Behav Brain Res 155: 135-146.

Quitkin FM, Mcgrath PJ, Stewart JW, Harrison W, Wager SG, Nunes E et al (1989). Phenelzine and imipramine in mood reactive depressives. Further delineation of the syndrome of atypical depression. Arch Gen Psychiatry 46: 787-793.

Regoli D, Boudon A, Fauchere JL (1994). Receptors and antagonists for substance $\mathrm{P}$ and related peptides. Pharmacol Rev 46: 551-599.

Riesenberg R, Rosenthal J, Moldauer L, Peterson C (2012). Results of a proof-of-concept, dose-finding, double-blind, placebo-controlled study of RX-10100 (Serdaxin $\AA$ ) in subjects with major depressive disorder. Psychopharmacology (Berl) 221: 601-610.

Rupniak NMJ (2003). Animal models of depression: challenges from drug development. Behav Pharmacol 14: 385-390.

Salomé N, Stemmelin J, Cohen C, Griebel G (2006). Selective blockade of NK2 or NK3 receptors produces anxiolytic- and antidepressant-like effects in gerbils. Pharmacol Biochem Behav 83: $533-539$.

Sandi C, Cordero MI, Ugolini A, Varea E, Caberlotto L, Large CH (2008). Chronic stress-induced alterations in amygdala responsiveness and behavior-modulation by trait anxiety and corticotropin-releasing factor systems. Eur J Neurosci 28: 1836-1848.

Santarelli L, Saxe M, Gross C, Surget A, Battaglia F, Dulawa S et al (2003). Requirement of hippocampal neurogenesis for the behavioral effects of antidepressants. Science 301: 805-809.

Santos MA, Rocha FL, Hara C (2008). Efficacy and safety of antidepressant augmentation with lamotrigine in patients with treatment-resistant depression: a randomized, placebo-controlled, double-blind study. Prim Care Companion J Clin Psychiatry 10: 187-190.

Sarginson JE, Lazzeroni LC, Ryan HS, Ershoff BD, Schatzberg AF, Murphy GM Jr (2010). ABCB1 (MDR1) polymorphisms and antidepressant response in geriatric depression. Pharmacogenet Genomics 20: 467-475.

Sarter M, Bruno JP (2002). Animal models in Biological psychiatry.. In: D'Haenen HAH, den Boer JA, Willner P (eds) Biological Psychiatry Vol. 1 (Wiley: Chicester, pp 37-44.

Shen HW, Yu AM (2009). Difference in desipramine metabolic profile between wild-type and CYP2D6-humanized mice. Drug Metab Lett 3: 234-241.
Sibille E, Wang Y, Joeyen-Waldorf J, Gaiteri C, Surget A, Oh S et al (2009). A molecular signature of depression in the amygdala. Am J Psychiatry 166: 1011-1024.

Singh AB, Bousman CA, Ng CH, Byron K, Berk M (2012). ABCB1 polymorphism predicts escitalopram dose needed for remission in major depression. Transl Psychiatry 2: e198.

Soubrié P, Simon P (1989). Les modèles animaux en psychopharmacologie. Confrontations psychiatriques 30: 113-129.

Steinberg R, Alonso R, Griebel G, Bert L, Jung M, Oury-Donat F et al (2001). Selective blockade of neurokinin-2 receptors produces antidepressant-like effects associated with reduced corticotropin-releasing factor function. J Pharmacol Exp Ther 299: 449-458.

Steru L, Chermat R, Thierry B, Simon P (1985). The tail suspension test: a new method for screening antidepressants in mice. Psychopharmacology (Berl) 85: 367-370.

Stewart JW, Garfinkel R, Nunes EV, Donovan S, Klein DF (1998). Atypical features and treatment response in the National Institute of Mental Health Treatment of Depression Collaborative Research Program. J Clin Psychopharmacol 18: 429-434.

Suman-Chauhan N, Grimson P, Guard S, Madden Z, Chung FZ, Watling K et al (1994). Characterisation of [125I][MePhe7]neurokinin B binding to tachykinin NK3 receptors: evidence for interspecies variance. Eur J Pharmacol 269: 65-72.

Surget A, Saxe M, Leman S, Ibarguen-Vargas Y, Chalon S, Griebel $\mathrm{G}$ et al (2008). Drug-dependent requirement of hippocampal neurogenesis in a model of depression and of antidepressant reversal. Biol Psychiatry 64: 293-301.

Surget A, Wang W, Leman S, Ibarguen-Vargas Y, Edgar N, Griebel $\mathrm{G}$ et al (2009). Corticolimbic transcriptome changes are statedependent and region-specific in a rodent model of depression and of antidepressant reversal. Neuropsychoparmacology 34: $1363-1380$

Surget A, Tanti A, Leonardo ED, Laugeray A, Rainer Q, Touma C et al (2011). Antidepressants recruit new neurons to improve stress response regulation. Mol Psychiatry 16: 1177-1188.

Tanti A, Belzung C (2010). Open questions in current models of antidepressant action. Br J Pharmacol 159: 1187-1200.

Trivedi MH, Rush AJ, Wisniewski SR, Nierenberg AA, Warden D, Ritz L et al (2006). Evaluation of outcomes with citalopram for depression using measurement-based care in STAR ${ }^{\star} \mathrm{D}$ : implications for clinical practice. Am J Psychiatry 163: 28-40.

Uhr M, Tontsch A, Namendorf C, Ripke S, Lucae S, Ising M et al (2008). Polymorphisms in the drug transporter gene ABCB1 predict antidepressant treatment response in depression. Neuron 57: 203-209.

van der Hart MG, de Biurrun G, Czéh B, Rupniak NM, den Boer JA, Fuchs E (2005). Chronic psychosocial stress in tree shrews: effect of the substance $\mathrm{P}$ (NK1 receptor) antagonist L-760735 and clomipramine on endocrine and behavioral parameters. Psychopharmacology (Berl) 181: 207-216.

van de Rest O, Geleijnse JM, Kok FJ, van Staveren WA, Hoefnagels WH, Beekman AT et al (2008). Effect of fish-oil supplementation on mental well-being in older subjects: a randomized, doubleblind, placebo-controlled trial. Am J Clin Nutr 88: 706-713.

Vancassel S, Leman S, Hanonick L, Denis S, Roger J, Nollet M et al (2008). n-3 Polyunsaturated fatty acid supplementation reverses stress-induced modifications on brain monoamine levels in mice. J Lipid Res 49: 340-348.

Varty GB, Cohen-Williams ME, Hunter JC (2003). The antidepressant-like effects of neurokinin NK1 receptor antagonists in a gerbil tail suspension test. Behav Pharmacol 14: 87-95.

Veenit V, Cordero MI, Tzanoulinou S, Sandi C (2013). Increased corticosterone in peripubertal rats leads to long-lasting alterations in social exploration and aggression. Front Behav Neurosci 7: 26.

Venna VR, Deplanque D, Allet C, Belarbi K, Hamdane M, Bordet R (2009). PUFA induce antidepressant-like effects in parallel to 
structural and molecular changes in the hippocampus. Psychoneuroendocrinology 34: 199-211.

Wallace-Boone TL, Newton AE, Wright RN, Lodge NJ, McElroy JF (2008). Behavioral and pharmacological validation of the gerbil forced-swim test: effects of neurokinin-1 receptor antagonists. Neuropsychopharmacology 33: 1919-1928.

Weiss JM, Kilts CD (1998). Animals models of depression and schizophrenia. In: Schatzberg $\mathrm{AF}$, Nemeroff $\mathrm{CB}$ (eds) The American Psychiatric Press Textbook of Psychopharmacology. American Psychiatric Press: Washington DC-London, pp 89-131. Willner P (1984). The validity of animal models of depression. Psychopharmacology 83: 1-16.

Willner P, Towell A, Sampson D, Sophokleous S, Muscat R (1987). Reduction of sucrose preference by chronic unpredictable mild stress, and its restoration by a tricyclic antidepressant. Psychopharmacology (Berl) 93: 358-364.

Willner P, Muscat R, Papp M (1992). Chronic mild stress-induced anhedonia: a realistic animal model of depression. Neurosci Biobehav Rev 16: 525-534.
Willner P, Scheel-Krüger J, Belzung C (2012). The neurobiology of depression and antidepressant action. Neurosci Biobehav Rev 37: 2331-2371.

Wong ML, Kling MA, Munson PJ, Listwak S, Licinio J, Prolo P et al (2000). Pronounced and sustained central hypernoradrenergic function in major depression with melancholic features: relation to hypercortisolism and corticotropin-releasing hormone. Proc Natl Acad Sci USA 97: 325-330.

Wood SK, McFadden KV, Grigoriadis D, Bhatnagar S, Valentino RJ (2012). Depressive and cardiovascular disease comorbidity in a rat model of social stress: a putative role for corticotropinreleasing factor. Psychopharmacology (Berl) 222: 325-336.

World Health Organization (2008): The Global Burden of Disease 2004 update http://www.who.int/healthinfo/global_burden_disease/GBD_report_2004update_full.pdf.

Yin OQ, Wing YK, Cheung Y, Wang ZJ, Lam SL, Chiu HF et al (2006). Phenotype-genotype relationship and clinical effects of citalopram in Chinese patients. J Clin Psychopharmacol 26: 367-372. 